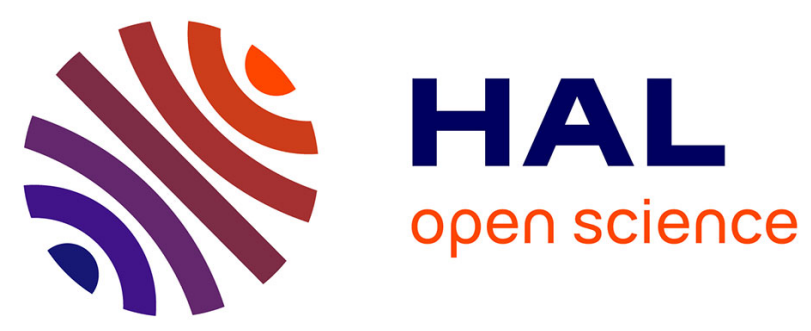

\title{
Reaction rates for the oxidation of highly sulphurised petroleum cokes : the influence of thermogravimetric conditions and some coke properties
}

Sylvain Salvador, Jean-Michel Commandre, Brian R. Stanmore

\section{To cite this version:}

Sylvain Salvador, Jean-Michel Commandre, Brian R. Stanmore. Reaction rates for the oxidation of highly sulphurised petroleum cokes: the influence of thermogravimetric conditions and some coke properties. Fuel, 2003, 82 (6), p. 715-720. 10.1016/S0016-2361(02)00363-0 . hal-01845408

\author{
HAL Id: hal-01845408 \\ https://hal.science/hal-01845408
}

Submitted on 8 Nov 2019

HAL is a multi-disciplinary open access archive for the deposit and dissemination of scientific research documents, whether they are published or not. The documents may come from teaching and research institutions in France or abroad, or from public or private research centers.
L'archive ouverte pluridisciplinaire HAL, est destinée au dépôt et à la diffusion de documents scientifiques de niveau recherche, publiés ou non, émanant des établissements d'enseignement et de recherche français ou étrangers, des laboratoires publics ou privés. 


\title{
Reaction rates for the oxidation of highly sulphurised petroleum cokes: the influence of thermogravimetric conditions and some coke properties ${ }^{\text {is }}$
}

\author{
S. Salvador*, J.-M. Commandré, B.R. Stanmore \\ Laboratoire de Génie des Procédés des Solides Divisés, Ecole des Mines d'Albi-Carmaux, Centre Energétique-Environnement, UMR 2392, \\ Campus Jarlard, route de Teillet, 81013 Albi CT Cedex 09, France
}

\begin{abstract}
The reaction with air of a large number (22) of high-sulphur petroleum cokes was studied by temperature-ramped thermogravimetric analysis. The kinetic parameters for each coke were established, based on BET surface areas. The oxidation rates $\left(\mathrm{kg}_{\mathrm{C}} \mathrm{m}^{-2} \mathrm{~s}^{-1} \mathrm{~atm}{ }^{-1}\right)$ were found to vary with sample mass. This was a result of limitations on oxygen transfer, despite the small masses and low heating rates used. Limitations were present both externally (from the crucible mouth to the bed surface) and internally (from the sample surface to the bed interior). A method to take these effects into account was adopted, based on an analysis of the relevant diffusion rates. Application of this method reconciled the rate data for four different sample masses, except at high temperatures. The formation of a partially fused ash crust is believed to be the reason for this latter effect.

The activation energies of the cokes varied between 195 and $280 \mathrm{~kJ} \mathrm{~mol}^{-1}$, and the absolute rates varied by a factor of 10 . They were between 1000 and 10,000 times higher than the average reactivity of carbon as reported in the literature. The elevated apparent rates are believed to have two causes, one in the combustion process and the other in the interpretation of the results. The first cause is the strong catalytic effect of the inorganic components, although the ash contents ranged only from 0.3 to $1.5 \%$. The most active metal is vanadium, which is present in significant concentrations. The effectiveness of $\mathrm{V}_{2} \mathrm{O}_{5}$ as a gasifying catalyst is believed to be due to its low melting point. Increasing sulphur content in the cokes produces no perceptible change in the combustion rates. The second cause for poor combustion correlation is the inadequacy of BET surface area for expressing combustion rates.
\end{abstract}

Keywords: Oxidation; Petroleum coke; Catalysis

\section{Background}

Petroleum coke is used extensively as a fuel, particularly in the cement industry. Its cost has fallen to virtually zero, but at the same time, the quality has declined. In particular, sulphur contents have risen to the order of $5-7 \%$ and the mineral matter content has also increased. These changes have led to modifications of the combustion systems of plants using the fuels. The work described here was part of an investigation into the use of petroleum cokes in the precalciners of cement kilns.

\footnotetext{
* Corresponding author. Tel.: + 33-5-63-49-31-27; fax: +33-5-63-49-3099

E-mail address: salvador@enstimac.fr (S. Salvador).
}

The oxidation rate of petroleum cokes has been extensively researched, both at lower temperatures in fixed beds and at higher temperatures in entrainment flow furnaces [1-9]. Results for the oxidation of a wide range of carbons were collected by Smith [10], corrected for internal mass transfer and oxygen concentration, and correlated as intrinsic kinetic rates based on BET areas. In his compilation of data, the petroleum cokes were somewhat anomalous in that the three studies reported had reactivities that were 2-50 times higher than his generalised correlation. The petcoke studies covered the range from 450 to $1800{ }^{\circ} \mathrm{C}$. On the other hand, the results for a number of graphites were 2-100 times lower than the correlation.

This divergence of over three orders of magnitude between the two extremes has been extensively discussed. 
The lowest reactivities reported were for purified, dense graphites. With these materials, the catalytic effect of minerals was absent, and the highly ordered structure meant that the oxygen encountered large areas of basal plane material. Since the main source of attack is at the carbon edges [11], the reactivities were understandably low.

The comparatively high reactivities exhibited by petroleum cokes have not received a satisfactory explanation. Two explanations are possible, the first dealing with the likelihood of efficient catalysis. Since petroleum cokes have passed through a liquid/plastic regime, it can be assumed that any mineral matter will be finely divided and dispersed throughout the solid. The catalytic metals will therefore be very active, as their history in the fluid phase would ensure intimate mixing and good catalyst/carbon contact.

The second explanation concerns the area specified for reaction. A reason for the spread of the reactivity of carbons with respect to nitric oxide NO has recently been proposed [12], based on the inadequacy of BET area to describe the active surface. When the BET areas were replaced by the surface areas associated with pores greater than $20 \mathrm{~nm}$ (called $\mathrm{Hg}_{20}$ ), the reactivity data for a number of widely different carbons, including some of the petroleum cokes tested here, collapsed onto the one Arrhenius plot. The same may be true for reaction with oxygen.

In this project, the reaction rates towards oxygen of a suite of 22 petroleum cokes used as precalciner fuel were established by temperature-ramped thermogravimetry. The reaction rates of some of them have previously been measured at higher temperatures in an entrainment flow furnace [13].

\section{Experimental}

The 22 petcokes were sampled at different industrial sites. The ultimate and proximate analyses of the five selected later to span a range of reaction rate are given in Table 1. Also shown are the elemental analyses for metals and a BET area as measured by nitrogen adsorption. The ashes were obtained by calcination overnight at $500{ }^{\circ} \mathrm{C}$ to avoid metal vaporisation. The metals were analysed by induction coupled plasma. The particle sizes were in the range -100 to $30 \mu \mathrm{m}$.

The thermogravimetric analyser used was a Seteram Model 92-16.18. The samples were weighed into a platinum crucible and a stream of air of $17 \mathrm{ml} \mathrm{min}^{-1}$ at STP was passed across the top. The temperature was increased at a rate of $3 \mathrm{~K} \mathrm{~min}^{-1}$ from ambient to burnout (around $550{ }^{\circ} \mathrm{C}$ for the smallest sample and over $700{ }^{\circ} \mathrm{C}$ for the largest). As the geometry of the crucible is important for the discussion of mass transfer which follows, a dimensioned sketch is given in Fig. 1.

The internal diameter of the crucible was $4.85 \mathrm{~mm}$ and the depth from the top to a large concave dimple in the base was $4.95 \mathrm{~mm}$. The purpose of the dimple was to house
Table 1

Properties of some petroleum cokes

\begin{tabular}{lccccc}
\hline Sample & 1 & \multicolumn{2}{l}{3} & 4 & 5 \\
\hline Proximate analysis (\% dry) & & & & & \\
Volatile matter & 5.17 & 10.48 & 10.96 & 11.09 & 10.14 \\
Ash & 0.5 & 0.33 & 0.12 & 3.35 & 0.47 \\
Ultimate analysis (\% daf) & & & & & \\
Carbon & 88.5 & 87.9 & 88.4 & 85.8 & 89.4 \\
Hydrogen & 1.94 & 3.51 & 3.70 & 3.5 & 3.60 \\
Sulphur & 6.00 & 7.47 & 6.16 & 5.85 & 4.02 \\
Nitrogen & 1.63 & 1.61 & 1.56 & 1.70 & 1.88 \\
BET area $\left(\mathrm{m}^{2} \mathrm{~g}^{-1}\right)$ & 6.3 & 4.5 & 6.2 & 4.8 & 5.3 \\
& & & & & \\
Hg $20\left(\mathrm{~m}^{2} \mathrm{~g}^{-1}\right)$ & 1.3 & 1.8 & 2.0 & 1.8 & 1.8 \\
Metal $(\%$ on coke) & & & & & \\
Copper $\left(\times 10^{-4}\right)$ & 6.05 & 9.05 & 3.81 & 3.10 & 1.89 \\
Iron $\left(\times 10^{-2}\right)$ & 17.4 & 6.15 & 2.02 & 3.81 & 0.93 \\
Manganese $\left(\times 10^{-4}\right)$ & 17.1 & 5.10 & 2.55 & 6.06 & 0.44 \\
Molybdenum $\left(\times 10^{-3}\right)$ & 2.63 & 0.70 & 1.73 & 1.66 & 1.40 \\
Potassium $\left(\times 10^{-3}\right)$ & 1.49 & 4.50 & 1.75 & 5.75 & 1.04 \\
Vanadium $\left(\times 10^{-1}\right)$ & 0.90 & 0.51 & 1.39 & 1.83 & 2.57 \\
\hline
\end{tabular}

the system thermocouple, but it meant that a small ( $3 \mathrm{mg}$ ) sample occupied only the annular space surrounding it. The bed depth is given as $e(\mathrm{~m})$ and the freeboard i.e. the distance from the top of the bed to the mouth of the crucible as $l(\mathrm{~m})$. Then $e+l=6.46 \mathrm{~mm}$.

Four sample masses were used in an initial oxidation study of one coke, namely $3,6,12$ and $24 \mathrm{mg}$. The approximate location of the bed surface for each mass is given in Fig. 1. As a result of these preliminary tests, an investigation was undertaken to influence the transfer of oxygen from the air stream to the interior of the bed. A technique was adopted to compensate for oxygen transfer limitations, both within the bed and to its surface.

Using the technique developed in this way, the reaction rates of 22 petcokes were measured and compared.

\section{Results and discussion}

The thermograms (mass versus time) for the four masses are shown in normalised form in Fig. 2. After an initial

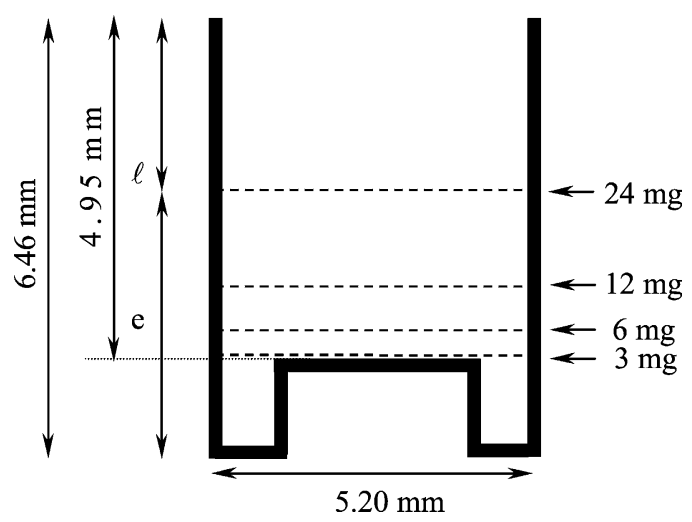

Fig. 1. Geometrical arrangement of the platinum crucible. 


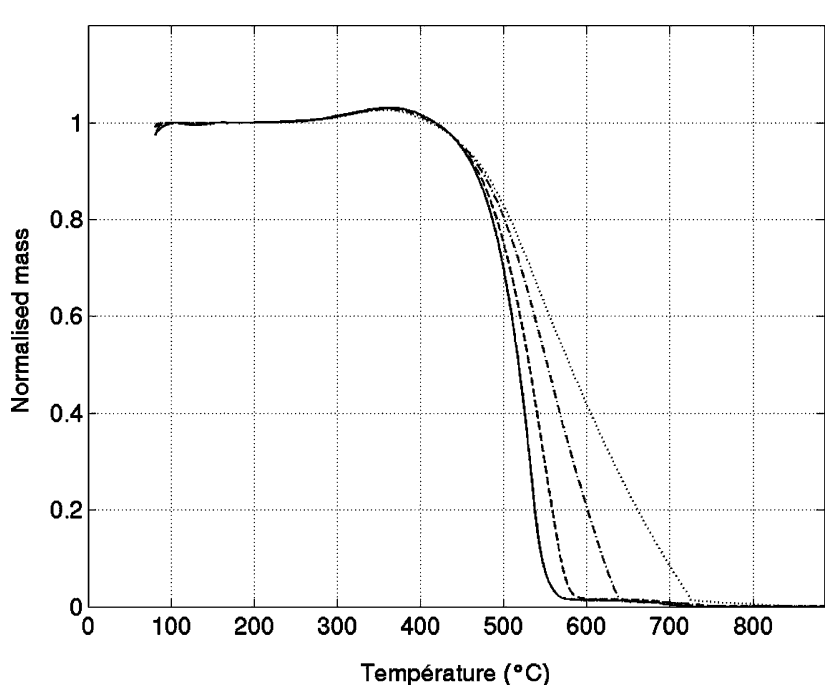

Fig. 2. Thermograms of the four sample masses; $17 \mathrm{ml} \mathrm{min}^{-1}$ at STP of air, $3 \mathrm{~K} \mathrm{~min}^{-1}$; (-) $3 \mathrm{mg}$; (- - -) $6 \mathrm{mg}$; (-..-) $12 \mathrm{mg}$; (..) $24 \mathrm{mg}$.

increase in mass due to the adsorption of oxygen, the masses fall to zero. There is a distinct effect of sample size on burnout, which indicates that mass transfer limitations are in operation. Such effects are not found with coal chars, but appear with soot or carbon black [16].

The apparent reaction rate, assuming first order kinetics, was calculated from

$-\frac{\mathrm{d} m}{\mathrm{~d} t}\left(\mathrm{~kg} \mathrm{~s}^{-1}\right)=k m S_{\mathrm{p}} P_{\mathrm{O}_{2}}$

where $m$ is the sample mass $(\mathrm{g}), t$ is time $(\mathrm{s}), k$ is the instantaneous isothermal reaction rate $\left(\mathrm{kg} \mathrm{m}^{-2} \mathrm{~s}^{-1} \mathrm{~atm}^{-1}\right)$, $S_{\mathrm{p}}$ is the active area of the particles $\left(\mathrm{m}^{2} \mathrm{~kg}^{-1}\right)$ and $P_{\mathrm{O}_{2}}$ is the partial pressure of oxygen (atm). This formulation assumes that the internal surface area is unchanged during burnout. The instantaneous oxidation rate was calculated over the burnout range from 0.05 to 0.85 .

In the present case, the comparatively high reaction rates of the coke leads to significant oxygen depletion in

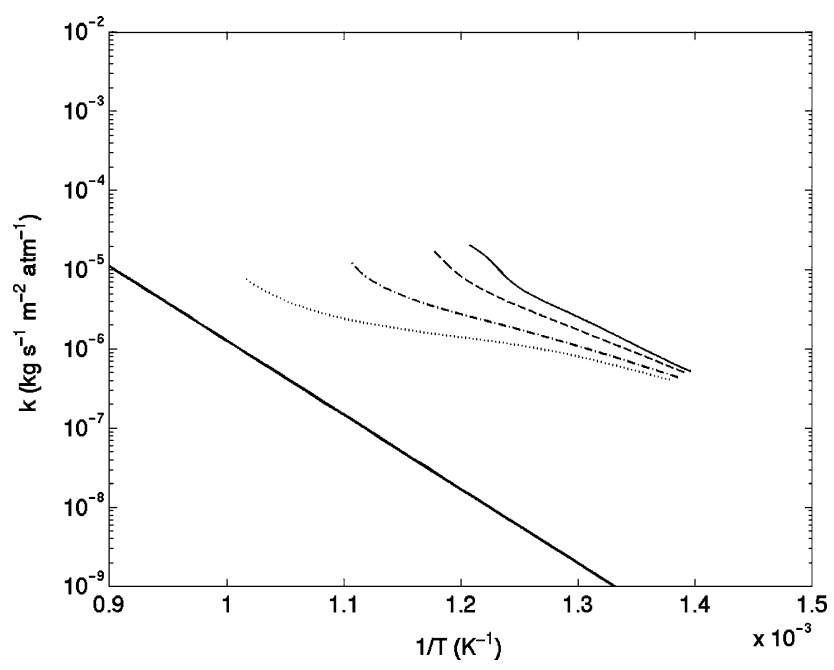

Fig. 3. Apparent reaction rates of the four sample masses, 0.05-0.85 burnout; ( - ) Smith correlation. Symbols as for Fig. 2. the system. This is clearly seen in Fig. 3 where the four reaction rates are plotted in Arrhenius form, based on BET areas. There is an apparent decrease in reaction rate $k$ and activation energy as the sample size increases. The smallest sample, which is least likely to be affected by diffusion limitations, shows the highest rate and closest agreement in activation energy to the generalised correlation of Smith [10] (also shown on the figure). Repeatability has been tested by running five identical tests. The maximum difference on reaction rate values was less than $10 \%$.

\subsection{Application of a method to eliminate mass transfer effects}

In order to correct the calculated reaction rates, it was necessary to estimate the extent of oxygen penetration into the bed, i.e. to calculate an effectiveness factor. This was derived from a monodimensional model involving the Thiele modulus of the bed [14]. The expression for oxygen flux at the bed surface in terms of displacement from the surface $z(\mathrm{~m})$ in an isothermal bed of depth $e(\mathrm{~m})$ is

$N_{\mathrm{O}_{2}}\left(\mathrm{~kg}_{\mathrm{O}_{2}} \mathrm{~m}^{-2} \mathrm{~s}^{-1}\right)=K C \int_{0}^{e} x_{\mathrm{O}_{2}} \mathrm{~d} z$

where $K$ is the rate of consumption of oxygen $\left(\mathrm{s}^{-1}\right), C$ is the total gas concentration $\left(\mathrm{kg} \mathrm{m}^{-3}\right)$ and $X_{\mathrm{O}_{2}}$ is the local mass fraction of oxygen. The rate constant, based on carbon removal used in Eq. (1), $k\left(\mathrm{~kg} \mathrm{~m}^{-2} \mathrm{~s}^{-1} \mathrm{~atm}^{-1}\right)$ is related to that based on oxygen consumption $K\left(\mathrm{~s}^{-1}\right)$ by

$K\left(\mathrm{~s}^{-1}\right)=\frac{\beta S_{\mathrm{p}} \rho_{\mathrm{b}} P}{C x_{\mathrm{bO}_{2}}} k$

where $\beta$ is the stoichiometric coefficient $(\mathrm{kg} \mathrm{O}$ per $\mathrm{kg}$ carbon), $\rho_{\mathrm{b}}$ is the bed density $\left(\mathrm{kg} \mathrm{m}^{-3}\right)$ and $x_{\mathrm{bO}_{2}}$ is the oxygen mass fraction in the bulk gas. In this case, carbon dioxide is assumed to be the oxidation product and $\beta$ is therefore $8 / 3$. The oxygen concentration at any position $z$ within the bed in relation to that at the surface $x_{\mathrm{sO}_{2}}$ is given by Ref. [14]

$$
\begin{aligned}
x_{\mathrm{O}_{2}}= & \frac{x_{\mathrm{SO}_{2}}}{1+\exp (-2 \theta)} \\
& \times\left[\exp (-2 \theta) \exp \left(\sqrt{\frac{K}{D_{\mathrm{e}}}} z\right)+\exp \left(-\sqrt{\frac{K}{D_{\mathrm{e}}}} z\right)\right]
\end{aligned}
$$

where $\theta=\mathrm{e} \sqrt{ }\left(K / D_{\mathrm{e}}\right)$, the bed Thiele modulus. The values of $\theta$ and $K$ (and hence $k$ ) can be found from the measured oxygen flux $N_{\mathrm{O}_{2}}$, which is calculated from the rate of carbon loss

$\frac{N_{\mathrm{O}_{2}}}{C x_{\mathrm{SO}_{2}}}\left(\mathrm{~m} \mathrm{~s}^{-1}\right)=\sqrt{K D_{\mathrm{e}}}\left[\frac{1-\exp (-2 \theta)}{1+\exp (-2 \theta)}\right]$

Since $K$ appears in $\theta$, an iterative data fitting is required. The effective diffusion coefficient $D_{\mathrm{e}}$ was found by the method of Satterfield [15] with tortuosity equal to 2.8 . With this 


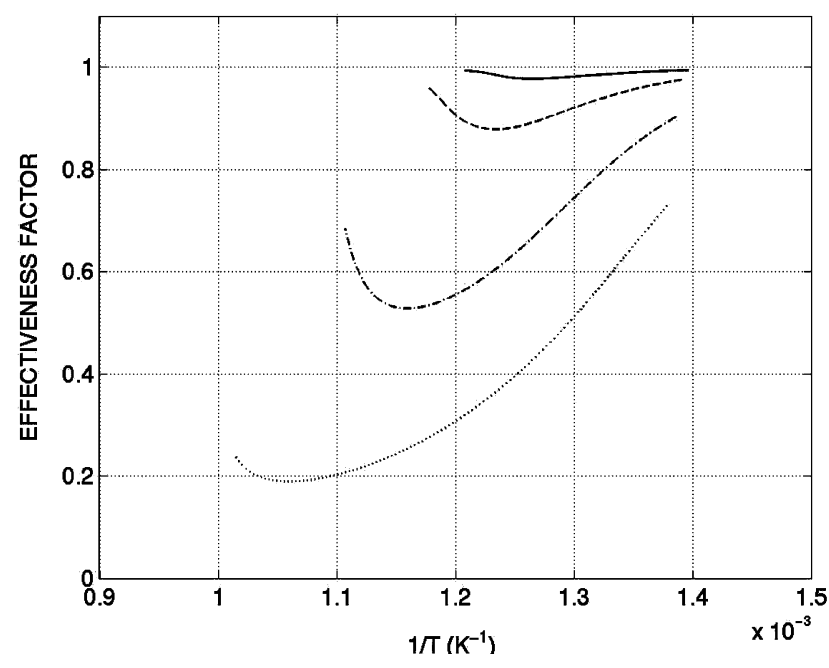

Fig. 4. Effectiveness factor in the bed of the four sample masses.

value, the reaction rate data for the different masses coincided. The effectiveness is then given by

$\eta=\frac{1-\exp (-2 \theta)}{\theta(1+\exp (-2 \theta))}$

The values found for the effectiveness in the thermogravimetric tests are shown in Fig. 4, and the values of $k$ in Fig. 5. There is almost complete penetration of oxygen into the bed for the $3 \mathrm{mg}$ sample $(\eta \approx 1.0$ in Fig. 4$)$. In contrast, the effectiveness of oxygen utilisation in the $24 \mathrm{mg}$ sample falls below 0.2 at higher temperatures. The effect on the Arrhenius plot with a correction for bed effectiveness, Fig. 5 shows that the plots for the larger samples now approach that of the smallest.

There is an apparent anomaly in Fig. 5 between the 12 and $24 \mathrm{mg}$ samples, where the rate calculated for the larger sample is higher than that of the smaller when 1/ $T>1.23 \times 10^{-3} \mathrm{~K}^{-1}$. In general, there is still a systematic effect of size on reaction rate. It was postulated that, this

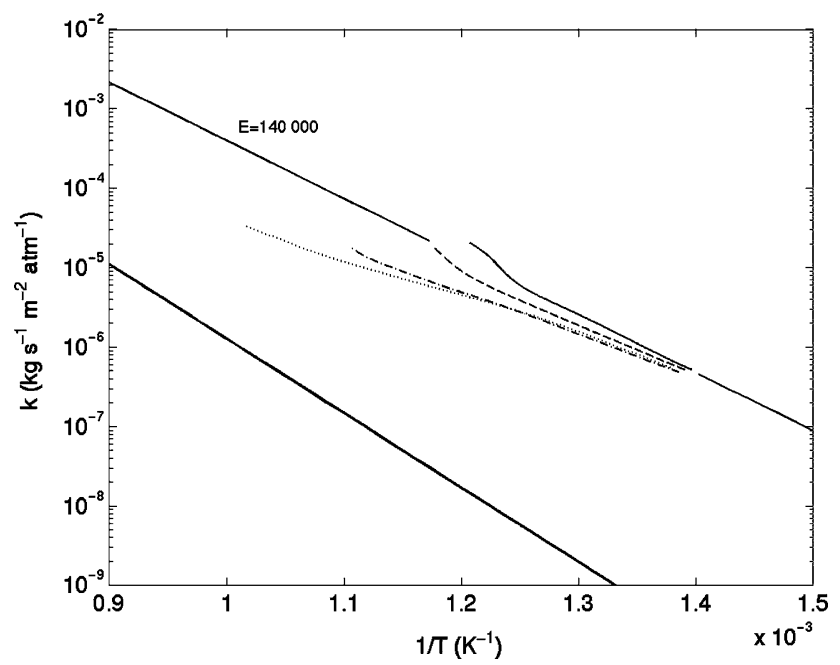

Fig. 5. Reaction rates of the four sample masses corrected for diffusion limitation inside the bed.

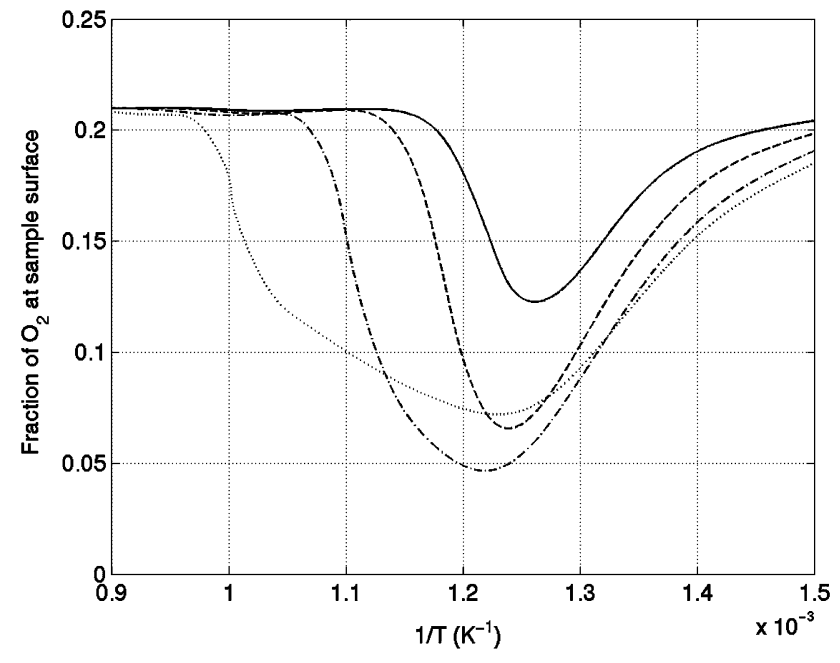

Fig. 6. Mole fraction of oxygen at the bed surface calculated with the monodimensional diffusion equation in the freeboard of the crucible.

results from a lowered oxygen concentration at the bed surface. It has been shown that molecular diffusion limits transport from the bulk flow [14]. Accordingly, allowance was made for any fall in oxygen concentration at the surface of the bed by application of a monodimensional diffusion equation for oxygen in the freeboard. The normalised concentration gradient of oxygen in the vertical $(z)$ direction is

$\nabla_{z \mathrm{O}_{2}}\left(\mathrm{~m}^{-1}\right)=\frac{N_{\mathrm{O}_{2}}-x_{\mathrm{O}_{2}}\left(N_{\mathrm{O}_{2}}+N_{\mathrm{CO}_{2}}\right)}{C D_{\mathrm{O}_{2}-\mathrm{CO}_{2}}}$

Here $N_{\mathrm{O}_{2}}$ and $N_{\mathrm{CO}_{2}}$ are the vertical fluxes $\left(\mathrm{kg} \mathrm{m}^{-2} \mathrm{~s}^{-1}\right)$ of oxygen and carbon dioxide, respectively, and $D_{\mathrm{O}_{2}-\mathrm{CO}_{2}}$ is the molecular diffusion coefficient of oxygen in carbon dioxide $\left(\mathrm{m}^{2} \mathrm{~s}^{-1}\right)$. The diffusion coefficient was calculated from $D_{\mathrm{O}_{2}-\mathrm{CO}_{2}}=1.7 \times 10^{-5}(T / 273)^{1.5} \mathrm{~m}^{2} \mathrm{~s}^{-1}$. The concentration gradient so derived was applied over the diffusion path length $l$ as shown in Fig. 2 to find the instantaneous surface concentration of oxygen $x_{\mathrm{SO}_{2}}$.

The oxygen concentrations ( $m o l$ fraction) estimated in this way are given in Fig. 6. There is significant oxygen depletion in all samples, with a minimum concentration for each occurring around $450-500{ }^{\circ} \mathrm{C}$. The minimum value of surface $\mathrm{O}_{2}$ concentration for the $24 \mathrm{mg}$ sample is found to be higher than that for the $12 \mathrm{mg}$ sample, because its surface is closer to the mouth of the crucible.

The reaction rates corrected for surface oxygen concentration are shown in Fig. 7. The anomaly between the 12 and $24 \mathrm{mg}$ samples is removed by the inversion in oxygen values. The $3 \mathrm{mg}$ sample line is now almost straight, with an activation energy of $170 \mathrm{~kJ} \mathrm{~mol}^{-1}$. At low temperatures, the other plots fall together with this line, but they diverge at progressively higher temperatures. In many cokes, there is a fall in reaction rate before a burnout of 0.85 is attained, probably produced by fused ash.

The points of divergence occur at burnouts of about 0.75 for the $3 \mathrm{mg}$ sample, 0.5 for the $12 \mathrm{mg}$ and 0.3 for 


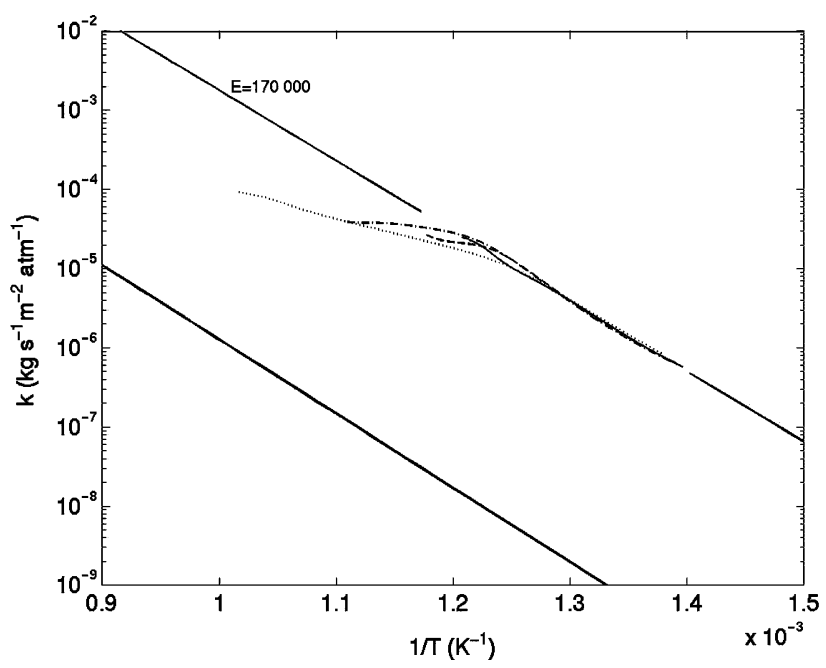

Fig. 7. Reaction rates corrected for diffusion both within and above the bed.

the $24 \mathrm{mg}$. This indicates that changes brought about by combustion produce the effects. The most obvious is the formation of an ash layer on the surface of the beds. It was noticed that the ash remaining after total burnout was grey in colour and formed a thin skin, which adhered to the bottom of the crucible. Some ash fusion had obviously taken place. Such a crust on the surface during oxidation would prevent the access of oxygen, and appear at lower burnouts with larger samples. The ash analyses in Table 1 indicate that the high sulphur content can act as a flux for the system, producing low melting point salts, and the slow heating would give time for reaction.

\subsection{Comparison of the reaction rates of 22 petcokes}

The results for all 22 petcokes are presented in Fig. 8. The range of activation energies is from 195 to

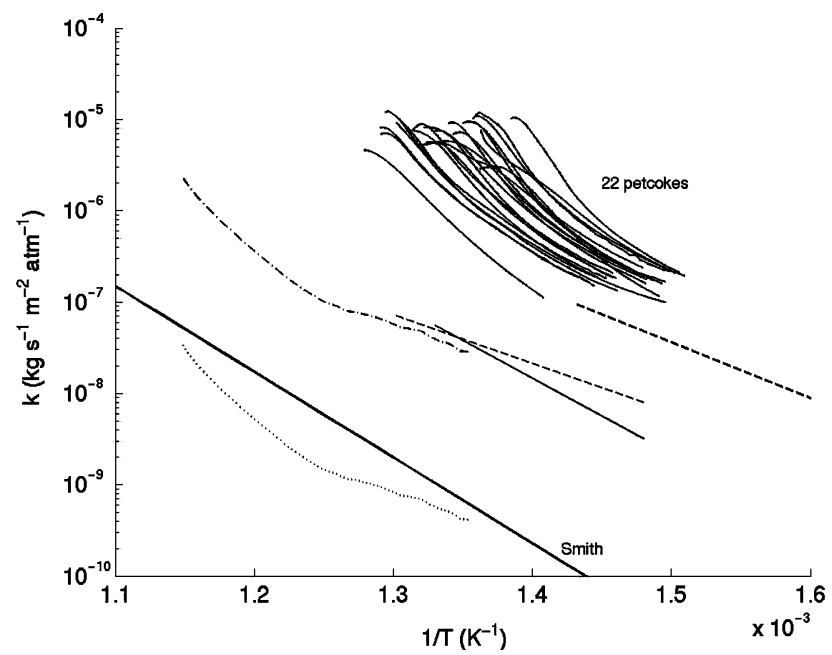

Fig. 8. Reaction rates of carbons; (..) activated carbon, BET area; (-.-.-) activated carbon, $\mathrm{Hg}_{20}$ area; (-) petcoke [5]; (- - -) diesel soot, uncatalysed [18]; (- - -) diesel soot, catalysed [18].
$280 \mathrm{~kJ} \mathrm{~mol}^{-1}$; the statistical error is $\pm 30 \mathrm{~kJ} \mathrm{~mol}^{-1}$. There is a spread of reaction rate of over one order of magnitude and the rate data so obtained are of the order of 100010,000 times higher than the correlation of Smith, with activation energies generally higher. It is of interest to note that there is an autocorrelation between the activation energies and the pre-exponential factors of the samples, similar to that found by Essenhigh [16] and Cuesta et al. [17]. The pre-exponential factors increase as the activation energies increase $\left(R^{2}=0.96\right)$.

In order to check that the equipment and technique give reliable results, an activated carbon of high BET area $\left(890 \mathrm{~m}^{2} \mathrm{~g}^{-1}\right)$ was also burned. The result, which is also shown in Fig. 8 falls close to the line of the Smith correlation, thus indicating that the technique gives results consistent with conventional values.

The petcokes thus represent a separate set of data with high apparent reaction rates. Two explanations are developed here to explain the excessively high reaction rate. The first concerns catalysis by the metals present, particularly by vanadium which is acknowledged as a good catalyst for low temperature carbon oxidation [18]. Vanadium and iron are present in concentrations in an order of magnitude greater than the other metals analysed, see Table 1.

Fig. 9 plots the reaction rate towards oxygen at $700{ }^{\circ} \mathrm{C}$ against the $\mathrm{V}_{2} \mathrm{O}_{5}$ content for five cokes, which span the range of reaction rate. The correlation coefficient is high at 0.93 . Vanadium pentoxide is thought to be active by virtue of its low melting point of $670{ }^{\circ} \mathrm{C}$ [19], giving a Tammann temperature of around $490 \mathrm{~K}$. The Tammann temperature is the temperature above which the oxide will begin to be mobile on the surface of the carbon, and thus be effective as a catalyst [11]. Other potential catalytic metals such as copper, iron, molybdenum, manganese, and potassium showed a zero or negative influence.

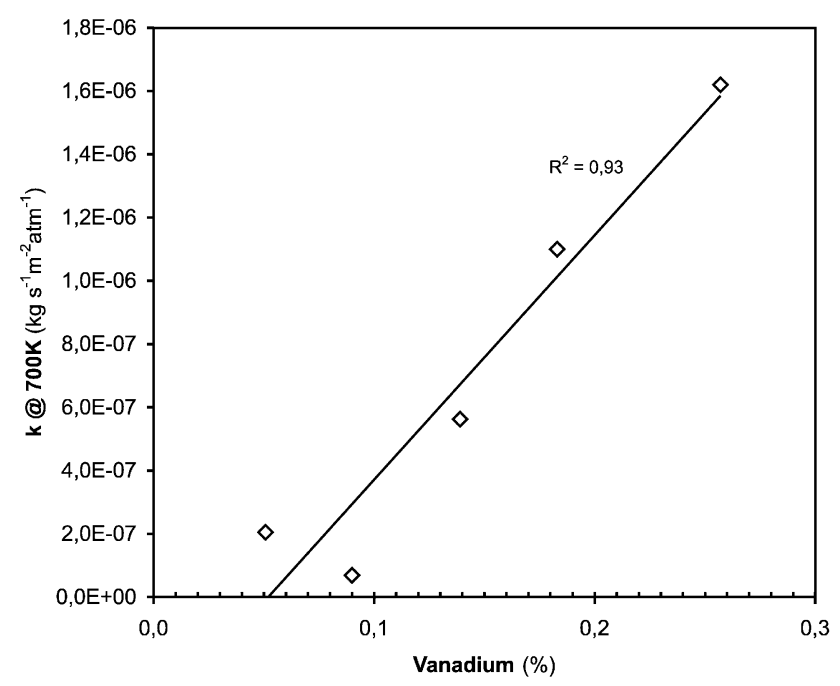

Fig. 9. Influence of vanadium on the corrected reaction rates of five petcokes at $700 \mathrm{~K}$. 
A plot of reaction rate versus sulphur content showed a slight negative trend $\left(R^{2}<0.2\right)$. Vanadium mixed with diesel soot is not subject to poisoning by sulphur [20], which is similar to the behaviour found here with petroleum coke.

The second explanation offered for the comparatively high reaction rate of the petroleum cokes relates to the conversion of the experimental mass loss data to a surface area basis. It has been demonstrated by Aarna and Suuberg with coal char [21] that micropores do not appear to participate in the oxidation reaction, which is consistent with the porosimetry results of Tyler for petcoke [5]. It has recently been shown by the authors [12] that when some CNO reactivity data were plotted not on the basis of BET area, but of $\mathrm{Hg}_{20}$ area, i.e. the area associated with pores above $20 \mathrm{~nm}$ in size as measured by mercury porosimetry and given in Table 1, a better correlation was obtained.

The reactive areas for soot (or carbon black) and petcoke are relatively easy to define, as with the former it is close to the geometric external area of the component spheres, and with the latter the $\mathrm{Hg}_{20}$ and BET areas are similar because micropores are virtually absent $[5,12]$. With coal chars, an extensive system of micropores contributes most to the BET surface areas. As a guide to the inherent reactivity of uncatalysed petroleum coke, the results of Tyler [5] are shown in Fig. 8. They lie well above the generalised correlation of Smith.

Some rates measured by Ahlström and Odenbrand [18] for the oxidation of diesel soot in the absence and presence of a vanadium pentoxide catalyst were calculated from their data, assuming a soot surface area of $100 \mathrm{~m}^{2} \mathrm{~g}^{-1}$ (the geometric external area of the soot spherules). The initial BET area of this soot was $35 \mathrm{~m}^{2} \mathrm{~g}^{-1}$ but rose to $270 \mathrm{~m}^{2} \mathrm{~g}^{-1}$ during burnout. For uncatalysed soot, the rates are below those of the least reactives of our cokes, see Fig. 8, but similar to the petcoke data of Tyler. They are also similar to value measured by us here for activated carbon, when the results are replotted on the $\mathrm{Hg}_{20}$ area basis of $12.9 \mathrm{~m}^{2} \mathrm{~g}^{-1}$. The reactivities of some uncatalysed carbons such as soot and carbon black lie in this region when correlated on the basis of BET (and hence $\mathrm{Hg}_{20}$ ) areas [22]. However, others are lower and lie near the Smith correlation [23].

The catalysed rates for soot reported by Ahlström and Odenbrand are similar to the least reactive petroleum coke in our tests Fig. 8. The catalyst they used was adsorbed as vanadate onto a substrate of $\gamma$-alumina, which was then calcined and intimately mixed with the soot. Their rates depended on the inverse of the particle size of the alumina, which indicates that when $\mathrm{V}_{2} \mathrm{O}_{5}$ is intimately mixed in the sample, such as a petcoke which has been through a plastic stage, the catalytic effect should be even greater.

We therefore conclude that the petcokes are apparently more reactive than most carbons for the two reasons specified above, namely the manner in which reactive surface area is specified and catalysis by vanadium. The uncatalysed rates should fall around the data of Tyler, which is approximately 70 times higher than the Smith correlation. Catalysis by vanadium then increases the rates by a further factor of 10- to 100-fold.

\section{Conclusion}

The apparent oxidation rates of 22 high sulphur petroleum cokes in air were measured by temperatureramped thermogravimetry. In order to extract accurate results from the DTG measurements, corrections for mass transfer limitations had to be introduced. The samples show elevated apparent rates for oxidation in the temperature range $300-500{ }^{\circ} \mathrm{C}$. The high rates are believed to be the result of two effects: (i) the catalytic effect of the vanadium present in the samples, and (ii) the method of specifying the active surface area. We found that the surface of the pores larger than $20 \mathrm{~nm}$ was a better surface area for comparative purposes than BET. Sulphur content appears to have little effect on the rates.

\section{References}

[1] Grillet Y, Rébaudières P, Guérin H. Bull Soc Chim Fr 1967;2423.

[2] Smith IW. Combust Flame 1971;17:303.

[3] Young BC, Smith IW. 18th Symposium (International) on Combustion. Pittsburgh: The Combustion Institute; 1982. p. 124.

[4] Mitchell RE, McLean WJ. 19th Symposium (International) on Combustion. Pittsburgh: The Combustion Institute; 1984. p. 1113.

[5] Tyler RJ. Fuel 1986;65:235.

[6] Jung K. Fuel 1987;66:774.

[7] Rybak W, Zembrzuski M, Smith IW. 21st Symposium (International) on Combustion. Pittsburgh: The Combustion Institute; 1988. p. 231.

[8] Stanmore BR. Fuel 1991;70:1485.

[9] Chen JY, Harris DJ, Smith IW, Zhang D-K, Wall TF, Stanmore BR. Proceedings of 1991 International Conference on Coal Science. Oxford: Butterworth/Heineman; 1991. p. 303.

[10] Smith IW. Fuel 1978;57:409.

[11] Baker RTK. Carbon and coal gasification. NATO ASI Series, Dordrecht: Martinus Nijhoff; 1986. p. 231.

[12] Commandré J-M, Stanmore BR, Salvador S. Combust Flame 2002; 128:211.

[13] Van de Steene L, Salvador S, Charnay G. Combust Sci Technol 2000; 159:255.

[14] Stanmore B, Gilot P, Prado G. Thermochim Acta 1994;240:79.

[15] Satterfield CN. Mass transfer in heterogeneous catalysis. Cambridge, MA: MIT Press; 1970. p. 59.

[16] Essenhigh RH, Misra MK. Energy Fuels 1990;4:171.

[17] Cuesta A, Martínez-Alonso A, Tascón JMD. Energy Fuels 1993;7: 1141.

[18] Ahlström AF, Odenbrand CUI. Appl Catal 1990;60:143.

[19] Lide DR, editor. Handbook of chemistry and physics, 82nd ed. Boca Raton: CRC Press. June 2001 p. 4-93.

[20] Ahlström AF, Odenbrand CUI. Appl Catal 1990;60:157.

[21] Aarna I, Suuberg EM. 27th Symposium (International) on Combustion. Pittsburgh: The Combustion Institute; 1998. p. 2933.

[22] De Soete G. Western States section meeting. Salt Lake city: The Combustion Institute; 1998.

[23] Neeft JPA, Nijhuis TX, Smakman E, Makke M, Moulijn JA. Fuel 1997;76:1129. 